\title{
Structural Characterization of Vanadium Phosphate Catalysts Prepared using a Di-block Copolymer Template
}

\author{
W. Weng*, Z. Lin**, N.F. Dummer**, J.K. Bartley**, G.J. Hutchings** and C.J. Kiely* \\ * Department of Materials Science \& Engineering, Lehigh University, Bethlehem, PA 18015, USA \\ ** Cardiff Catalysis Institute, School of Chemistry, Cardiff University, Cardiff, CF10 3AT, UK
}

The selective oxidation of n-butane to maleic anhydride (MA) by vanadium phosphate catalysts $\left((\mathrm{VO})_{2} \mathrm{P}_{2} \mathrm{O}_{7}\right)$ has been studied since the 1980's [1]. In general, the commercial vanadium phosphate catalyst precursor $\left(\mathrm{VOHPO}_{4} \cdot 0.5 \mathrm{H}_{2} \mathrm{O}\right.$ phase) is prepared by a method denoted as the VPO route, whereby isobutanol is used as both solvent and reductant for $\mathrm{V}_{2} \mathrm{O}_{5}$, and $\mathrm{H}_{3} \mathrm{PO}_{4}$ is used as a source of phosphorus.

In this study, we utilize a di-block copolymer, 2-poly (styrene-alt-maleic acid) (PSMA) as a template to influence the crystallinity and morphology of a vanadium phosphate catalyst precursor. $\mathrm{V}_{2} \mathrm{O}_{5}$ and $\mathrm{H}_{3} \mathrm{PO}_{4}$ were reacted in isobutanol in the presence of a small amount of PSMA. The precursors produced are denoted as P1 (PSMA: $\mathrm{V}_{2} \mathrm{O}_{5}$ weight ratio $=1: 28,500$ ) and P2 (PSMA: $\mathrm{V}_{2} \mathrm{O}_{5}$ weight ratio $\left.=2: 28,500\right)$. These precursors were activated in a butane/air mixture at $400^{\circ} \mathrm{C}$ in a fixed bed micro-reactor to produce the corresponding activated catalysts denoted as $\mathrm{C} 1$ and $\mathrm{C} 2$, respectively. From XRD analysis and catalytic performance testing, the precursors produced were found to have a high degree of crystallinity and could be activated in a much shorter time (i.e. a matter of hours instead of days) when compared to precursors obtained from standard preparation routes.

Scanning electron microscopy (SEM) was used to characterize the morphology of the precursors and activated catalysts. Precursor P1 (Fig. 1(a)) has characteristic rosette-type agglomerates of angular hemihydrate platelets, while P2 (Fig.1(b)) exhibited many more isolated rhombic crystallites and some occasional spherical particles. Transmission electron microscopy (TEM) and selected area electron diffraction analysis (Fig. 2) indicates that these rhomboidal crystals are [001] oriented $\mathrm{VOHPO}_{4} \cdot 0.5 \mathrm{H}_{2} \mathrm{O}$ hemihydrate platelets and the spherical particles are $\mathrm{VO}\left(\mathrm{H}_{2} \mathrm{PO}_{4}\right)_{2}$ phase material. As shown in Fig. 2, the rhombic platelets in P2 have much sharper tips than those in P1 due to the increased amount of the polymer template which gives a stronger structure directing effect. The long straight pairs of terminating facets at the platelet edge has a characteristic intersection angle of $\sim 143^{\circ}$ which correspond to the (140) and $(1 \overline{4} 0)$ facet planes of the $\mathrm{VOHPO}_{4} \cdot 0.5 \mathrm{H}_{2} \mathrm{O}$ phase. Upon in-situ activation, the $\mathrm{VOHPO}_{4} \cdot 0.5 \mathrm{H}_{2} \mathrm{O}$ [001] platelets in both $\mathrm{P} 1$ and $\mathrm{P} 2$ transformed topotactically into [100] oriented $(\mathrm{VO})_{2} \mathrm{P}_{2} \mathrm{O}_{7}$ rhomboidal platelets in $\mathrm{C} 1$ and $\mathrm{C} 2$ having subtle morphology differences (Fig. 3 (a)). The minority spherical particles were found to persist in catalyst C2. Higher magnification BF TEM micrographs of a rhombic platelet in catalyst C2 are shown in Figs. 3 (b) and (c). Small oblong crystallites were observed in interior (Fig. 3 (b)) showing the [100] projection of $(\mathrm{VO})_{2} \mathrm{P}_{2} \mathrm{O}_{7}$ with (010) and (001) facet planes, while the rim is serrated on (012) and $(0 \overline{1} \overline{7})$ facet planes (Fig. 3 (c)). Our SEM and TEM analyses support the notion that the di-block polymer template has a structure directing effect which gives us some control over the morphology and crystallinity of the vanadium phosphate catalyst precursors produced. Our detailed microstructural observations will be correlated with catalytic performance measurements that have been performed on these vanadium phosphate catalysts. 


\section{References}

[1] J.W. Johnson et al., J. Am. Chem. Soc. 106 (1984) 8123.

[2] The authors acknowledge financial support from the NSF - Materials World Network Program (Grant \# DMR-0709887).
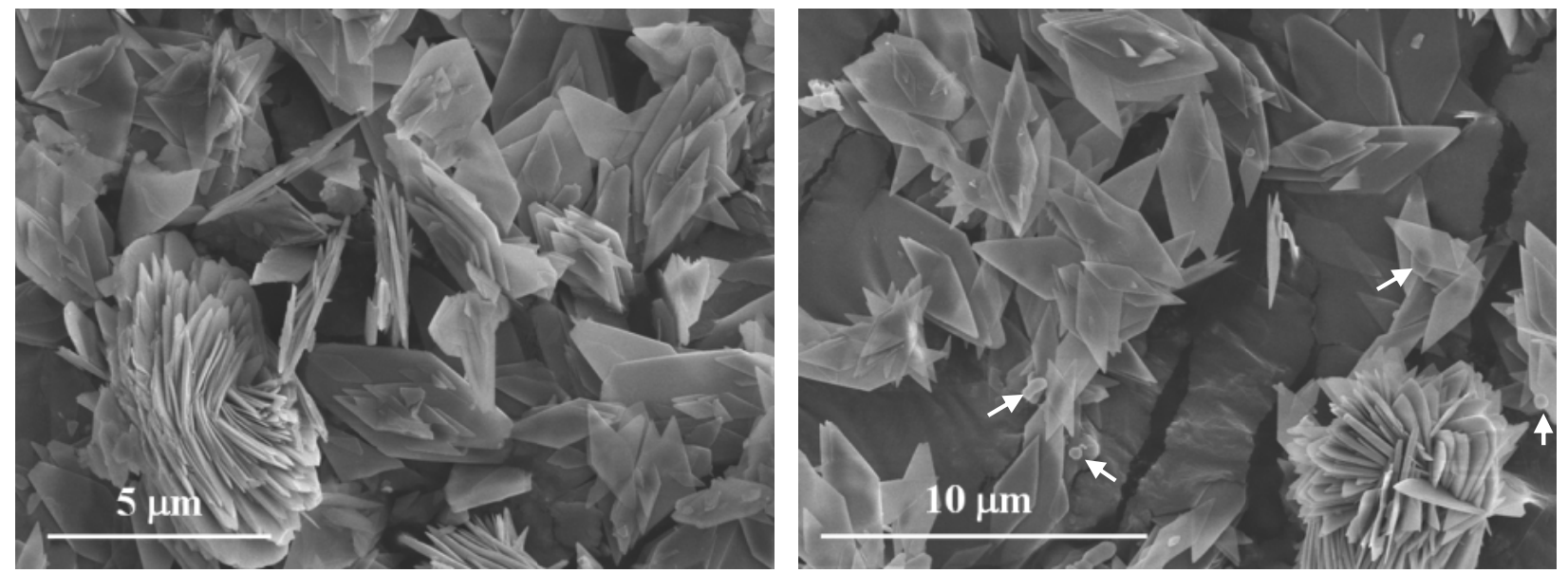

Figure 1. SEM micrographs of the precursors (a) P1 and (b) P2 (spherical particles are arrowed).
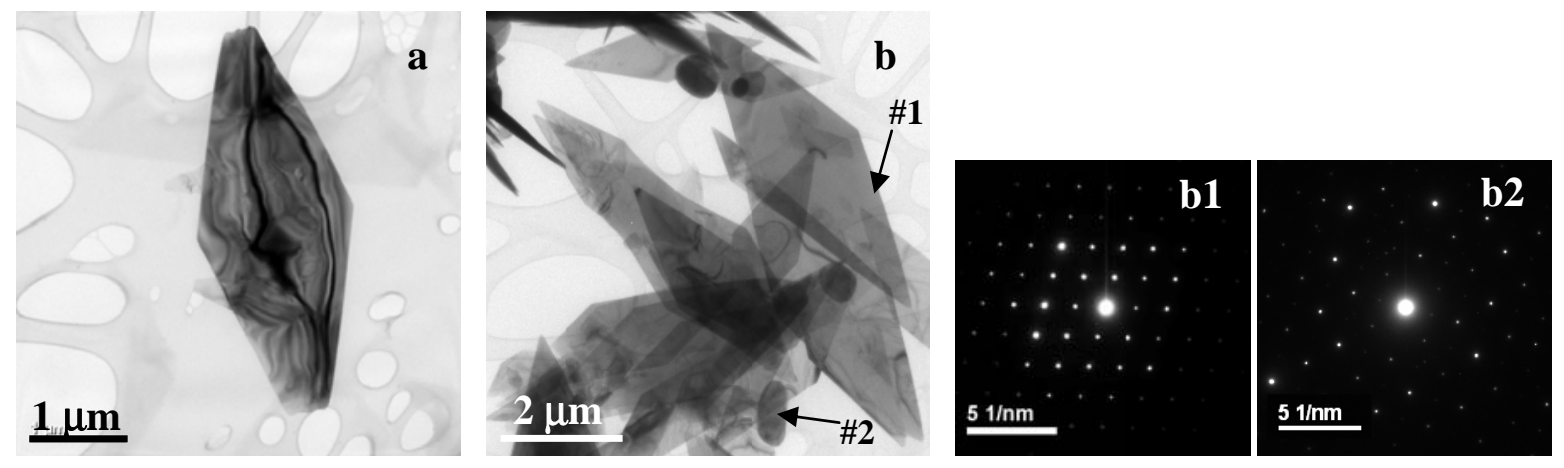

Figure 2. BF TEM micrographs of the precursors (a) P1 and (b) P2; SADP's from (b1) rhombic platelet (\#1) - [001] $\mathrm{VOHPO}_{4} \cdot 0.5 \mathrm{H}_{2} \mathrm{O}$ and (b2) sphere (\#2) - [001] $\left(\mathrm{VO}\left(\mathrm{H}_{2} \mathrm{PO}_{4}\right)_{2}\right)$.
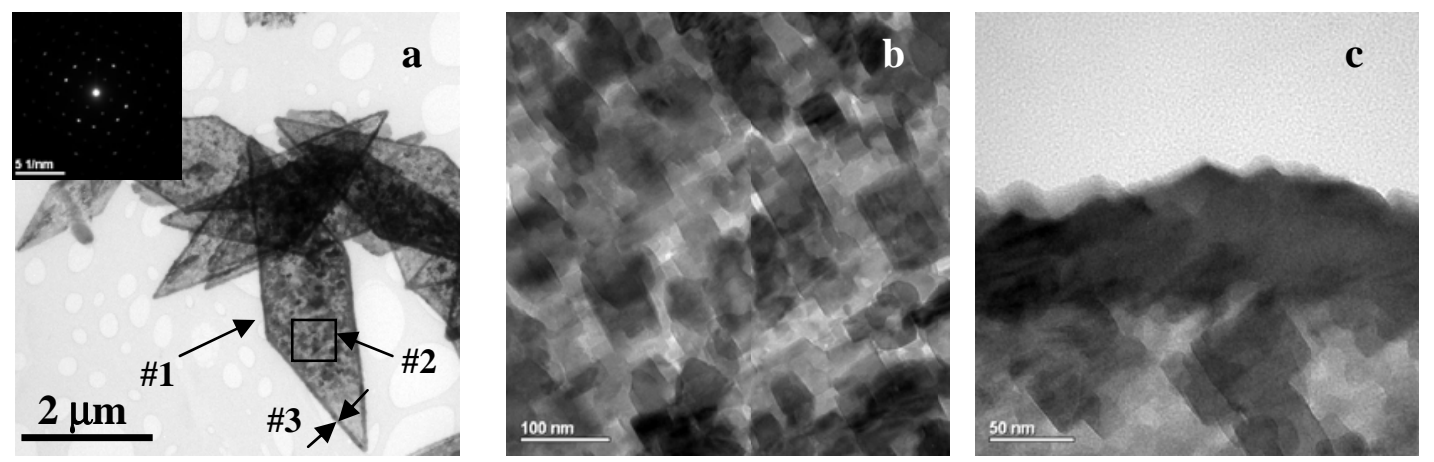

Figure 3. BF TEM micrographs of (a) activated catalyst C2 (inset SADP from rhombic platelet (\#1) - [100] (VO) ${ }_{2} \mathrm{P}_{2} \mathrm{O}_{7}$ ); higher magnification BF TEM micrographs of (b) the interior (\#2) and (c) rim region (\#3) of rhombic platelet (\#1). 